\title{
Smart Trolley with Automatic Billing System using Arudino
}

\author{
Shishir.R.Patil1 ${ }^{1}$, Shridhar N. Mathad ${ }^{2}$, S.S.Gandhad ${ }^{3}$, M.C. Ellemmi ${ }^{4}$ \\ ${ }^{1}$ Electrical and Electronics Department, K.L.E DR MSSCET, Belagavi, India \\ 2 Department of Engineering Physics, K.L.E Institute of Technology, Hubballi, India \\ ${ }^{3}$ Dept of Physics, P.C.Jabin Science College Hubballi-580031, Karnataka, India, \\ ${ }^{4}$ Jain college of Engineering and Research, Belgavi, Karnataka, India
}

\begin{abstract}
Nowadays, shopping malls (supermarkets) are almost developed with much technological advancement. A shopping mall is mall where we get different items like glass items, toys, kitchen sets ,groceries, decorative items and so many. Lots of people like to shop because of attractions like discounts, home delivery and so on. People have to wait in long queues especially on weekends and customer has to patiently wait for his turn. This is a time-wasting process due to the busy schedule of people and feels bored and are not happy by the services provided in billing counter. To avoid these problems we have introduced an effective and highly advance system which also helps us during COVID-19 period: an effective way for social distancing. In order to tackle this unique problem for customers especially in billing the system proposed is Smart trolley as when the items are put it gets scanned and purchased item and its amount displayed parallel on LCD automatically. It uses RFID technology which can scan huge no items and saves valuable time of customers as well as shopping mall.
\end{abstract}

KEYWORDS: Automatic Billing System, Arudino, Smart Trolley, Billing System

https://doi.org/10.29294/IJASE.8.3.2022.2268-2273

(C2021 Mahendrapublications.com, All rights reserved

\section{INTRODUCTION}

Metropolitan cities are crowded with people in shopping malls to buy their daily needs. As the market is growing bigger day by day with variety of products and consumer taste has changed[1-3] .Shopping malls are centre of attraction because of discounts in products, cashless transaction, variety of products like household, decorative, kitchen ,sports, education, stationeries which are all available under one roof [3-6]. So in this paper we are proposing a new technology especially in billing which saves the time of customer by effective and efficient billing using smart trolley [7-9]. The shopping malls presently use RFID tags which are tagged for every product which is within trolley and scan many times. The highly time consuming situation is observed where customer wait for long queues for only one item. RFID can scan as many as items which is infinite when we see over barcodes. The space required to install LCD, RFID Reader, and microcontroller is limited such that trolley turns out to be efficient [10-14]. It's also solves key factors like insufficient information of product, pitfall in prices on items. So we came for unique solution for smart trolley.

In Existing technology we need more human and material resources lot of time is wasted in scanning the items, making the bills ready and items can be read for shorter distances only ,barcodes need external power supply so in order to meet all the requirements of customer we proposed a smart trolley using RFIDS [14-15].The proposed paper focuses on updated technology of RFIDS, Saves precious time of customers by fast canning of products, scanning of items for long distances[16].The exaggerated shopping trolley system assistances the consumers in reducing the significant amount of time those consumers used to expend in shopping and it contains real-time informs on the records are also provided in the store management unit. If clients wishing to eliminate the product from the cart that they have taken they can do it by the use of a key. Once buying is over, the total amount will be displayed in the LCD and billing can be accomplished by using QR code. At the exit point checking of consignment and packing of merchandise can be done. In order to make shopping to a lesser extent difficult for shoppers in malls/shops, various strategies planned for clever purchasing trolleys. We have adopted a new methodology in which there is no need of server and there is no issue with connectivity and communication up to $1.8 \mathrm{Km}$. This methodology also provided the facility of paying bill at the cart itself employing $\mathrm{HC}-12$ transmitter for communication up to $1.8 \mathrm{Km}$ and RFID technology is used for fast and accurate

*Corresponding Author: shishirparil137@gmail.com / physicssiddu@gmail.com

Received: 05.12.2021

Accepted: 25.02.2022

Published on: 22.02.2022

Shishir R Patil et al., 
scanning of products. Our new idea is "Human Guided Smart Cart" [16-18]. The concept is designed into a smaller version of the automated self-checkout system on a shopping trolley with a user interface screen which allows customers to make payment for items scanned and placed in the trolley before leaving the exit of the store which release pressure at the tills during peak hours, advances in manufacturing, distribution and information combined with the urbanization of modern society, socio-demographical changes created the so-called new consumer, mall managers often need to track manually each stock available and sold in the large centre, which can be onerous [19-20].

These challenges require innovative solutions, which served to motivate the ideas demonstrated in this paper RFID (Radio Frequency Identification) Technology is used. Every item or product is attached with a RFID tag and this product is scanned using RFID reader which is attached with a trolley. Customer purchase different items and put them in the trolley. Price of that total items and also names will be displayed on LCD (Liquid Crystal Display) screen which is also attached with a trolley.

\section{MATERIALS AND METHODS}

\subsection{FUNCTIONING OF RFID}

The Fig. 1 shows the functioning of RFID which has RFID Reader and RFID tag which is transponder. RFID tag in conjunction with antenna and microchip transmits the data to the reader. A tag are attached to product as and when products are dropped and come in contact with reader tag transmits information. The total data of item is

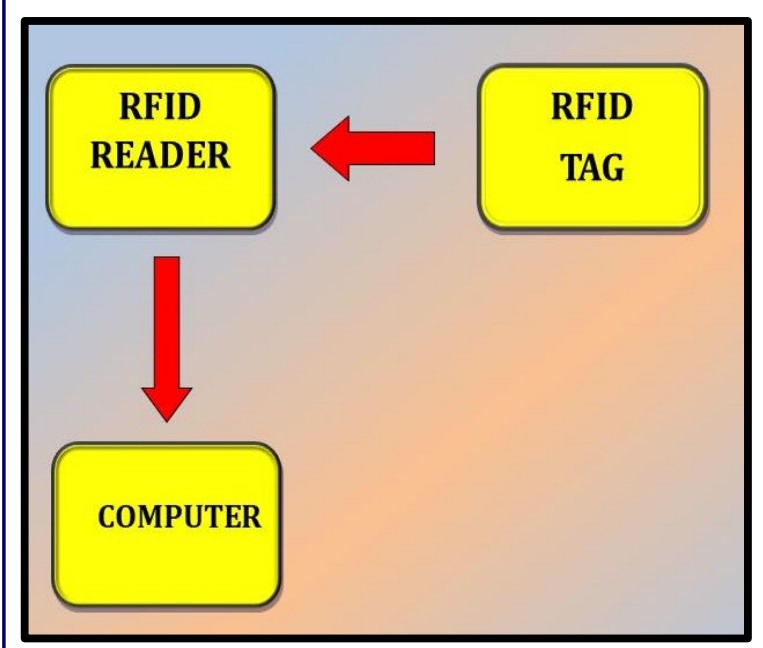

properly communicated to computer and finally stores the data [1-2].

Fig.1 Illustration of RFID

\subsection{FRAME WORK OF PROPOSED SYSTEM}

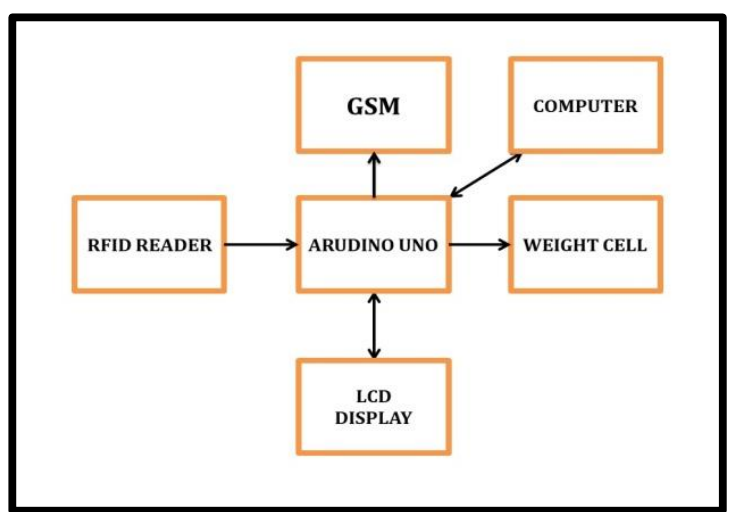

Fig.2 Frame Work of Present System

\section{a) RFID READER}

The RFID reader retrieve the information from tag which is attached to item, The reader takes data in digital form through radio waves. The reader acts as transmitter asking the information to tags and tags as receiver pass relevant data to reader.[5]

The RFID Reader can work under various frequencies firstly low frequency range $(125 \mathrm{kHz}-$ $134 \mathrm{kHz}$ ) with distance of $10 \mathrm{~cm}-30 \mathrm{~cm}$,secondly high frequency range $(13.56 \mathrm{MHz})$ with distance of $1 \mathrm{~m}$,thirdly ultra high frequency $(865-928 \mathrm{MHz})$ up to $1.5 \mathrm{~m}-2 \mathrm{~m}$

\section{B) RFID Tags}

The RFID tags falls into two classes active tags and passive tags. Active tags which produce their own energy because of self battery and passive tags as the name says it depends on external energy for its operation and they are generally used because of minimum cost and available in different geometries.

\section{C) Arduino Uno}

The detailed information of product is stored in microcontroller with series of instructions in programming language. The Arduino Uno is a microcontroller which has fourteen digital input/output pins. It can be externally supplied by power through USB.

\section{D) Weight cell}

The customer with malpractice can be caught by putting weight cell at check out point near security. If the weight of 20 items is ' $x$ ' but if final weight is ' $\mathrm{x}+\mathrm{y}$ ' where $\mathrm{y}$ is increased weight for which customer has not paid the bill.

\section{E) Server}

The information stored in microcontroller is passed to server through media of GSM. The 
server keeps the track of items stored in store and the bill paid by customer.

\section{F) Liquid Crystal Display}

The output of microcontroller is given to LCD. It can display sixteen characters in one line. Its uses 16*2 display. The customers get the data of item as the items are dropped in trolley by displaying Item name, item quantity, item amount with spacing. When items are dropped they get added otherwise gets subtracted. The information of purchased products will be seen on LCD with clarity and list is tabulated below.

\subsection{Differences between Existing and Proposed} Technology

The Table. 2 shows the differences of Existing technology which is barcode with pitfalls which consumes lots of time in billing and proposed technology a very efficient technology with upgraded features and customer friendly trolley system in conjunction with RFID [4-6].

Table1.Item purchased Information display on LCD

\begin{tabular}{|c|c|c|}
\hline ITEM & WEIGHT & AMOUNT \\
\hline RICE & $1 \mathrm{Kg}$ & 44 \\
\hline CADBURY & 5 & 25 \\
\hline VESSEL & 1 & 70 \\
\hline SUGAR & $1 \mathrm{~kg}$ & 45 \\
\hline
\end{tabular}

Table 2Difference between BARCODE and RFID

\begin{tabular}{|c|l|l|}
\hline Parameter & \multicolumn{1}{|c|}{ BARCODE } & \multicolumn{1}{c|}{ RFIDS } \\
\hline Line Of Sight & $\begin{array}{l}\text { It can scan one tag at } \\
\text { time }\end{array}$ & It can scan 100 tags at time \\
\hline Operation & $\begin{array}{l}\text { Barcode can read } \\
\text { data }\end{array}$ & RFIDS can read and write data \\
\hline Material & $\begin{array}{l}\text { It is made of paper so } \\
\text { can't be reused }\end{array}$ & It is made of plastic hence reusable \\
\hline Data & Small amount of data & Large Amount of data \\
\hline Read range & $\begin{array}{l}\text { Can read data at } \\
\text { distance of inches }\end{array}$ & Can read data at distance of feet \\
\hline Technology & Optical(laser) & Radio frequency \\
\hline Tags & Not Everlasting & Everlasting \\
\hline Cost & Reasonable & Expensive \\
\hline
\end{tabular}

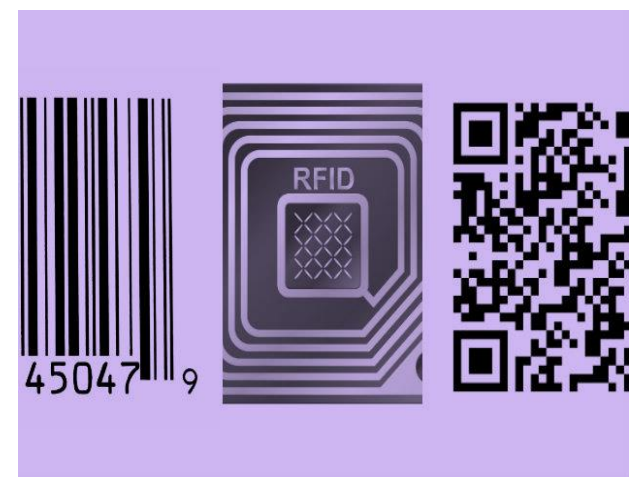

Fig.3 Glimpses of RFID and Barcode

\subsection{Analysis of Program}

STEP 1: Start the program

STEP II: Initialization of system by assigning values to flag

STEP III: Search for RFID tags if found read data from memory otherwise repeat the task

STEP IV: When total tags are found which are displayed on LCD
STEP V: When items are added the cost will be cumulative else subtractive

STEP VI: Data is fed to counter when upload key is pressed

STEP VII: Send data to customer mobile number STEP VIII: Stop the task

\subsection{Working Model of Smart trolley}

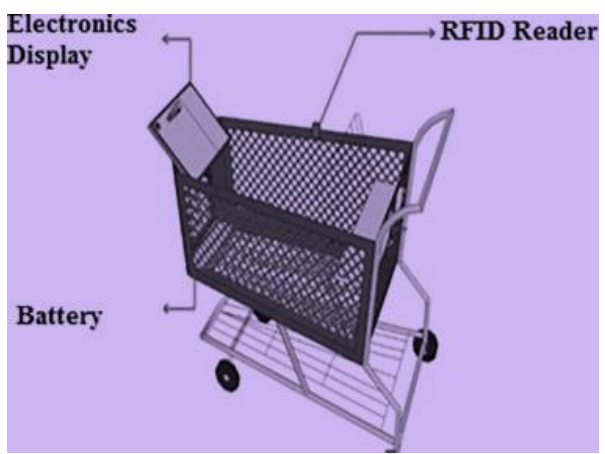

Fig.5 Physical View of Smart trolley 


\subsection{Pictorial Representation}

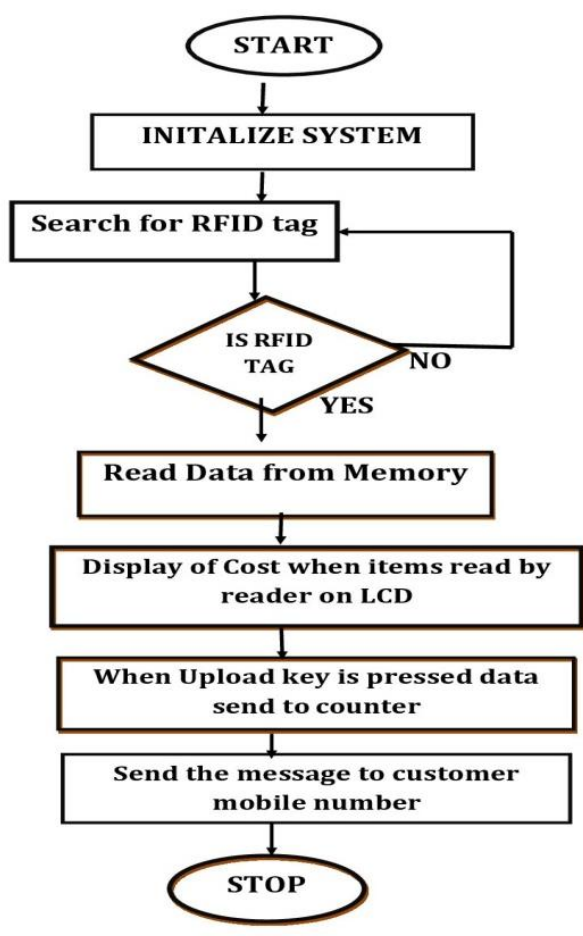

Fig.4 Flow Chart of proposed work

\section{RESULTS AND DISCUSSION}

All the experimental parts were discussed above, in which proposed system LCD is used to display the product information in terms of cost and weight. The proposed model is easily accessible, does not require special training and convenient to use. The manpower is decreased and will save time that the user spends in billing queue. Many users can be attended in same time which is useful for retailers and customers. Time efficiency and cost efficiency are guaranteed by this smart billing system. Smart trolley envisions simplifying the billing procedure by facilitating customers in creating a shopping session which lasts until the customer commands it to be cleared [21] and preserves the data of each product in the basket by using RFID tags to make the entry. It also facilitates in keeping the shopping experience in budget by displaying the total cost to the customer. Emerging trend of online shopping, which cuts down the hassle, at the same time that shopping at stores introduction of environment friendly smart carts and smart baskets not only help the stores to eliminate the surge but also serve to reduce the usage of paper, the number of employees making it more economical and unnecessarily wasted in printing copies of bills .Thus the use of RFID based smart trolleys is of major significance or importance interest and welfare to the society. The ESP attached to the system makes it far more compatible by giving the whole information of the shopping available on the android cell phones [2-6, 21].
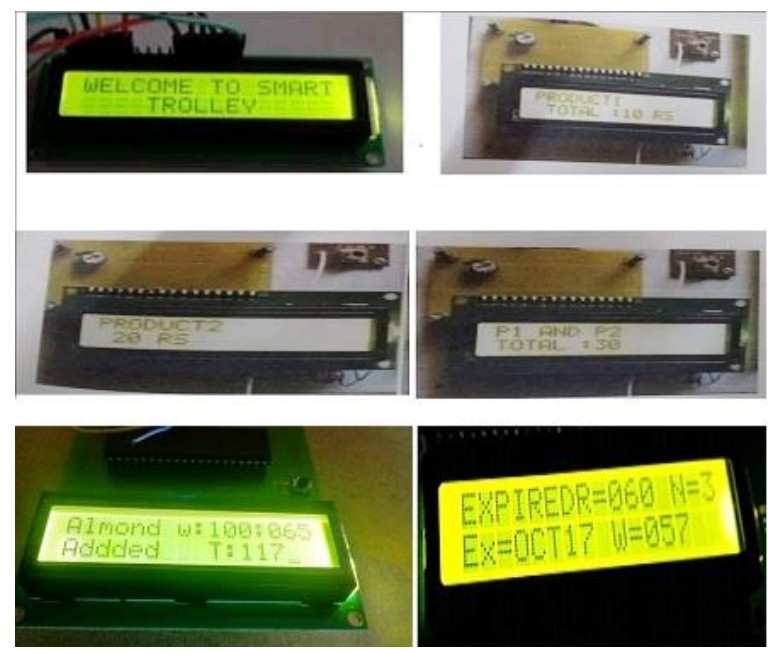

Fig.6 LCD Display of Various Process Involved

The results of shopping done by customers are shown on Liquid Crystal Display in terms of cost, weight, item name and in some cases, display will guide you that product is expired where customers have to be cautious. As the RFID Reader Scans the items from RFID tag the Item name along with cost and weight are displayed this process continues as when items are added and amount of items is cumulative in process. As the items are removed the amount will be subtracted due to expiry of item or item may be disliked. Smart trolley is equipped with cell which measures the weight of purchased items such that keen observation can be done on customers if any malpractices are performed during billing time. Let us illustrate with an example when the weight of 20 items is $\mathrm{X}$ but the displayed weight is $\mathrm{X}+3,2 \mathrm{X}$ which means actual value and measured value are different. It avoids unnecessary use of paper where printouts are eliminated and they experience shopping by making budget where prices are hiked and where they are lowered these forms a tool of good saving of money.

\section{CONCLUSION}

In the present study, we have implemented successfully a feasible technology based on RFID to help customers in abundance and saves precious time especially in billing which is highly tedious task waiting for our turn. Though RFID can scan huge items at once but every item should be tagged .Trolley turns to be smart with inbuilt features of tags and readers not consuming much space and thus make its very attractive for customers.

\section{Shishir R Patil et al.,}




\section{REFERENCES}

[1] Shankar,S. K., Balasubramani, S., Basha, S. A., Ariz Ahamed S., Kumar Reddy, N. S. 2021. Smart Trolley for Smart Shopping with an Advance Billing System using IoT, 5th International Conference on Computing Methodologies and Communication (ICCMC), pp. 390-394,

[2] Sahare P.S., Gade A., RohankarJ. 2019. A Review on Automated Billing for Smart Shopping System Using IOT, Review of Computer Engineering Studies, 6(1) 1-5.

[3] Das, T. K., Tripathy A. K., Srinivasan, K.2020, A Smart Trolley for Smart Shopping, International Conference on System, Computation, Automation and Networking (ICSCAN), pp. 1-5,

[4] Hanooja, T., Raji, C. G., Sreelekha, M., Koniyath, J., Muhammed Ameen V., Mohammed Noufal, M.2020. Human Friendly Smart Trolley with Automatic Billing System, 4th International Conference on Electronics, Communication and Aerospace Technology (ICECA), pp. 1614-1619,

[5] Jaishree, M., Lakshmi prabha, K. R. S., Jeyaprabha, Mohan, K.2021. Smart Shopping Trolley Using IOT, 7th International Conference on Advanced Computing and Communication Systems (ICACCS) pp. 793796,

[6] Athauda, T., Marin, J. C. L., Lee J., Karmakar, N. C.2018. Robust Low-Cost Passive UHF RFID Based Smart Shopping Trolley, in IEEE Journal of Radio Frequency Identification, 2(3) 134-143.

[7] Sanap, M., Chimurkar P., Bhagat, N. 2020.SMART-Smart Mobile Autonomous Robotic Trolley, 4th International Conference on Intelligent Computing and Control Systems (ICICCS), pp. 430-437,

[8] Kowshika, S., Madhu mitha, S. S., Madhu Varshini, G., Megha V., Lakshmi, K.2021. IoT based Smart Shopping Trolley with Mobile Cart Application, 7th International Conference on Advanced Computing and Communication Systems (ICACCS) pp. 11861189,

[9] Naveenprabu, T., Mahalakshmi, B., Nagaraj, T,. Kumar, S.P.N., Jagadesh, M.2020. IoT Based Smart Billing and Direction Controlled Trolley, 6th International Conference on Advanced Computing and Communication Systems (ICACCS) pp. 426429,

[10] Dev, M. K., Kannan, R., Agarshan, M., Karthik S., Lakshmi, K., Automated Billing Smart Trolley and Stock Monitoring, 2021, 5th
International Conference on Computing Methodologies and Communication (ICCMC) pp. 500-505,

[11] Kumar Yadav, B., Burman, A., Mahato, A., Choudhary M., Kundu, A. 2020. Smart Cart: A Distributed Framework, 2020 IEEE 1st International Conference for Convergence in Engineering (ICCE) pp. 210-213,

[12] Khadka, G., Feng J., Karmakar, N. C.2019. Chipless RFID: A Low-cost Consumer Electronics in the Retail marketplace for Moving Item Detection, IEEE 8th Global Conference on Consumer Electronics (GCCE) pp. 618-621,

[13] Sutagundar, A., Ettinamani M., Attar, A.2018. Iot Based Smart Shopping Mall, Second International Conference on Green Computing and Internet of Things (ICGCIoT), pp. 355-360,

[14] Rupanagudi S. R. 2015. A novel video processing based cost effective smart trolley system for supermarkets using FPGA, International Conference on Communication, Information \& Computing Technology (ICCICT) pp. 1-6,

[15] Merilaeinen, O., Wernle M. E., Voutilainen, J. 2007.New properties of UHF RFID transponders on metal with microstrip antennas, 3rd European Workshop on RFID Systems and Technologies, pp. 1-7.

[16] Iyappan, P., Jana, S. S., Anitha, S., Sasirega T., Venkatesan, V. P. 2016. An Enhanced Shopping Model for Improving Smartness in Markets using SABIS architecture,International Conference on Wireless Communications, Signal Processing and Networking (WiSPNET) pp. 140-145,

[17] Shailesh, S., Shrivastava Deb, P., Chauhan R., Tyagi, V.2021. Smart Trolley, International Conference on Advance Computing and Innovative Technologies in Engineering (ICACITE), 2021, 242-245,

[18] Dev, M. K. Kannan, R. Agarshan, M. Karthik S. Lakshmi, K. 2021.Automated Billing Smart Trolley and Stock Monitoring," 5th International Conference on Computing Methodologies and Communication (ICCMC) pp. 500-505,

[19] Sarala, T., Sudha, Y. A., Sindhu, K. V., Suryakiran C., Nithin, B. N.2018. Smart Electronic Trolley for Shopping Mall, 3rd IEEE International Conference on Recent Trends in Electronics, Information \& Communication Technology (RTEICT) pp. 2422-2427,

[20] Bita, A. A., Saud Al-Humairi S. N., Binti Mohamad Azlan, A. S.2021.Towards A Sustainable Development Cities Through 
Smart Shopping Trolly: A Response to the Covid-19 Pandemic, IEEE 11th IEEE Symposium on Computer Applications \& Industrial Electronics (ISCAIE) pp. 141-145,

[21] Pavni Swaroop, AkshitaParasari, Mansi Singh, Shobha Rajput, 2020. A Review paper on Smart Trolley System forAutomated Billing using RFID and IoT, International Journal of Creative Research Thoughts (IJCRT), 8(7) 2978-2982. 